\title{
Numerical Analysis of Integral Characteristics for the Condenser Setups of Independent Power-Supply Sources with the Closed-Looped Thermodynamic Cycle
}

\author{
Olga V. Vysokomornaya, Genii V. Kuznetsov, and Pavel A. Strizhak \\ National Research Tomsk Polytechnic University, 30 Lenin Avenue, Tomsk 634050, Russia \\ Correspondence should be addressed to Olga V. Vysokomornaya; vysokomornaja@tpu.ru
}

Received 24 May 2014; Revised 5 August 2014; Accepted 13 October 2014

Academic Editor: Christopher Gunaseelan Jesudason

Copyright (C) 2015 Olga V. Vysokomornaya et al. This is an open access article distributed under the Creative Commons Attribution License, which permits unrestricted use, distribution, and reproduction in any medium, provided the original work is properly cited.

The mathematical model of heat and mass transfer processes with phase transition is developed. It allows analysis of integral characteristics for the condenser setup of independent power-supply plant with the organic Rankine cycle. Different kinds of organic liquids can be used as a coolant and working substance. The temperatures of the working liquid at the condenser outlet under different values of outside air temperature are determined. The comparative analysis of the utilization efficiency of different cooling systems and organic coolants is carried out.

\section{Introduction}

The existence of stable and accessible energy resources for the technological process is important during the planning of some industrial productions. Nowadays, the natural gas is one of the most common and widely used types of fossil fuel for the electrical and heat energy generation [1]. It is known that Russia is the primary supplier of natural gas in European and Asian countries [2,3]. Therefore, the Russian mineral companies implement the large-scale construction of gas pipelines both in western and east directions (gas pipelines such as The South Stream, The Power of Siberia, etc.) to expand the market outlet and increase the reliability of gas supply for consumers.

Moreover, production operations of the gas pipeline system are also associated with the necessity of energy resources utilization. Despite the fact that the compressor stations are the main energy consumers consisting of the facilities supporting the gas pipeline system operational integrity, the hundreds of smaller electricity consumers are located along the gas pipelines.

The construction and operation of new gas pipelines are very difficult process, especially for the Power of Siberia gas transmission system, that will be located in the Eastern
Siberia and the Far East of Russia. This territory is characterized by the existence of vast areas with less developed power engineering infrastructure. Therefore, the use of independent power-supply plants is the only one possible way of electric power supply for gas pipeline stations and other equipment. The problem of centralized power supply is not so relevant for linear facilities of the South Stream gas pipeline. However, the electricity prices for industry in Europe are much greater than in Russia [4]. It in fact stimulates the gas transmission operators to search for more profitable power-supply sources. The independent power-supply plants can also be such alternative energy sources.

Nowadays, more than 100 low-powered (up to $4 \mathrm{~kW}$ ) independent power-supply plants operate in the territory of Russian Far East. It has the closed-looped thermodynamic cycle (Figure 1) and uses natural gas as a fuel. The main advantages of such energy source are capable of standalone operation during long time and high fuel utilization efficiency.

A lot of breakdowns of independent power-supply plants occur every year in spite of listed above advantages. It leads to reducing the gas pipeline system safety in whole [5]. In particular, according to the data of enterprise operating the power-supply plants there are several causes of technical 


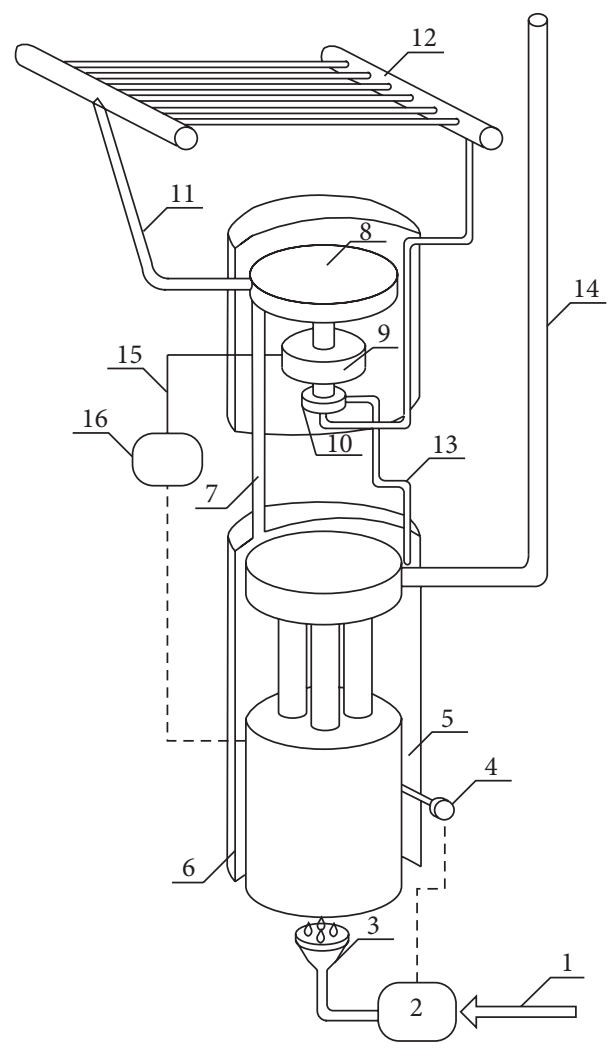

FIGURE 1: Schematic illustration of power-supply plant with the closed-looped thermodynamic cycle: 1 : fuel inlet; 2 : fuel supply panel; 3: fuel burner; 4: thermostat; 5: organic liquid; 6: steam generator; 7: steam; 8: turbine; 9: AC generator; 10: pump; 11: steam supply in a condenser; 12 : condenser; 13: condensed fluid outlet; 14 : exhaust stack; 15: input cables of alternating current to the rectifier; 16: electric service panel.

emergency: the loss of flame for a fuel burner (about $21 \%$ from all quantity of breakdowns), the mechanical problem for a turbine (about 25\%), and the extremely high temperature in a condenser (about 20\%). The detailed analyses of first and second problems are impossible due to the structural features of independent power-supply plant and manufacturer requirements. The air cooled condenser is placed beyond the housing of power-supply plant. It allows analyzing modes and establishing the reasons of high organic working substance temperature at the outlet of the condenser.

Heat transfer enhancement from the condenser pipes and use of alternative working substance may be the one of the problem solution of the high temperature at the condenser outlet. Experimental investigations are complicated by the necessity to exclude the independent power-supply plant from technological process. Besides a large quantity of measurement instruments must be used for different parameters detection. It leads to considerable material costs. Therefore, the numerical simulation is more suitable.

The purpose of the present paper is the numerical research on heat and mass transfer integral characteristics of a condenser working substance in independent power-supply plant under the different heat transfer conditions with outside air and under the conditions of using the different types of organic working substance.

\section{Problem Statement}

The independent electric power plant (Figure 1) has the following operation cycle [6]. The energy released during the fuel combustion process is used for the heating and the evaporation of organic working substance (dichlorobenzene) in the steam generator 6 . The steam of working liquid transfers to the turbine blades 8 . It leads to rotation of the turbine rotor. The last one is connected with the rotor of AC generator 9. After turbine the working substance transfers to the tubes of air condenser setup 12. It consists of 2 banks of finned tubes with inner diameter $D_{\text {in }}=38 \mathrm{~mm}$ combined by the common headers. The spacing between condenser pipes is $L \approx 0.15 D_{\text {in }}$. The organic working substance is chilled in the condenser. Then the liquid is returned to the steam generator 6 by the pump 10. Also working substance is used for lubrication of bearings. Then the cycle is repeated.

The main feature of the electric power plant (Figure 1) is the use of condensed working substance (dichlorobenzene) for lubricating the friction bearing of turbogenerator rotor. Therefore, it is necessary to choose alternatively dichlorobenzene such organic heat transfer agent that would have good lubricating properties, high operating temperature, and chemical inertness to power plant materials. The polyethylsiloxane (PES-5) suits these requirements [7].

It was assumed that the condenser pipes are located parallel to the horizon (without tilting). Also, the two phases working flow and the condensed fluid have satellite direction (Figure 2). The condensing process in a single tube of the condenser was simulated. The characteristic dimensions (length and diameter) of this tube are identical with the dimensions of condenser pipes integrated with the headers. Such statement of the problem is explained by the uniformity construction of condenser cooling channels.

A scheme (Figure 3) of the solution domain was accepted. It was supposed that the vapors of working liquid are supplied to the condenser pipe at a coexistence temperature $T_{s}$. The heat flux is removed from the vapors to the outside air by means of heat transfer through the pipe wall. The phase transition occurs. The condensate film is formed on the interior face of pipe. The condensate film thickness $(\delta)$ is increased during the vapor moving through the pipe. The vapor fraction $\left(\varphi_{v}\right)$ in the liquid-vapor mixture is decreased. If the phase transition completed, the further heat transfer leads to decreasing temperature of the working liquid.

The condensing process was considered to be accomplished if the vapor fraction in the liquid-vapor mixture was equal to a standard value [6] declared by the power-supply plant manufacturer.

The several assumptions were accepted during the simulation process.

(1) It was supposed that the vapors of working liquid are supplied to the condenser in a condition of dry steam, because the vapors temperature and pressure correspond to this condition [6]. 


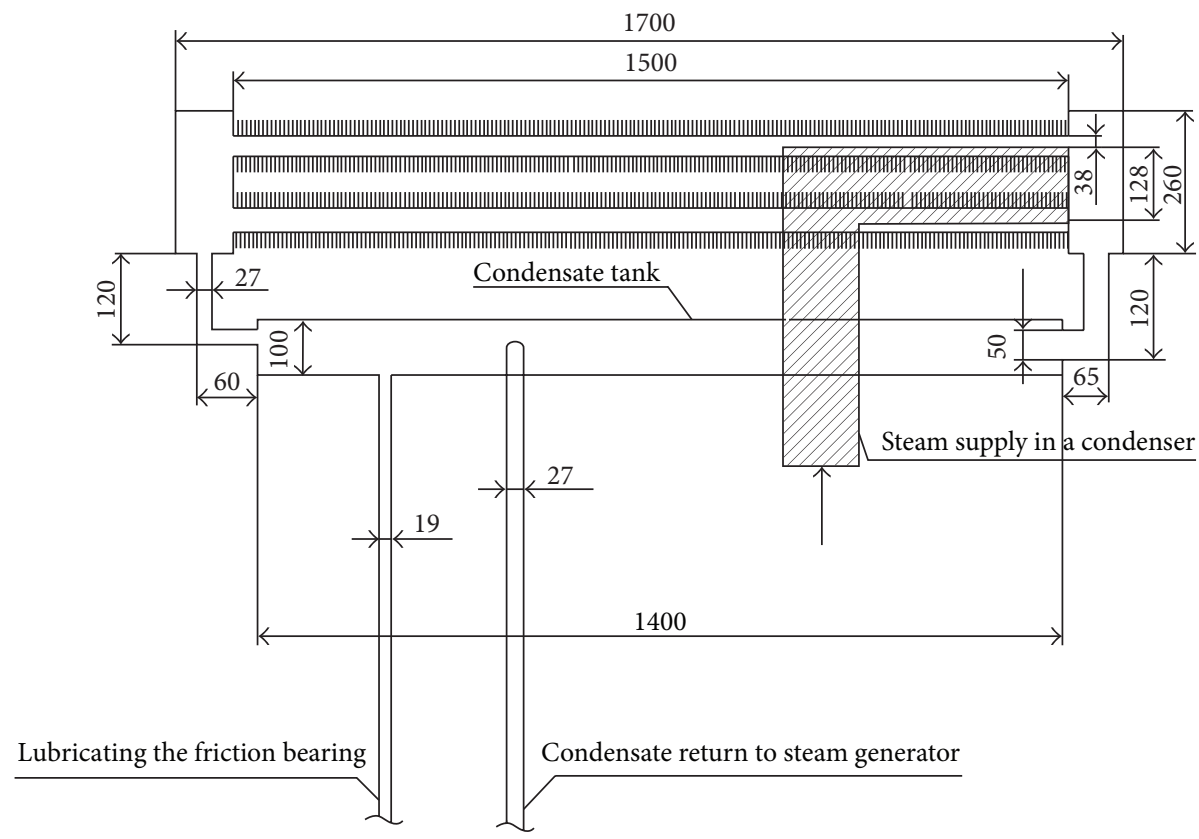

FIgURE 2: Schematic illustration of a condenser (frontal view).

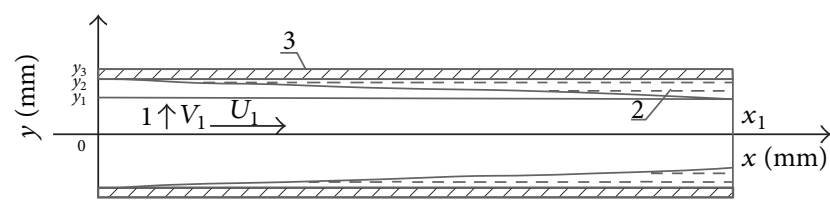

FIGURE 3: A scheme of the solution domain: 1: vapors of the working fluid; 2: condensed working fluid; 3: pipe wall; 4: outside air.

(2) The heat transfer coefficient $\left(\alpha_{1-2}\right)$ for the process of vapor condensation was calculated by means of the dependences [8] and its value was considered as a constant during the process. The analysis of the physical problem statement shows that the accounting of $\alpha_{1-2}$ change along the length of condenser pipe leads to the significant complication of the model under the condition of minimal results change.

(3) The vapors of a working substance were considered as the perfect gas in a first approximation. The parameters of a real working substance are difficult to define experimental due to lack of the suitable sensors in the condenser setup.

(4) The thermophysical properties of the liquid-vapor mixture of a working substance were calculated in accordance with a rule of additivity.

(5) It was considered that the thickness of the condensate film $(\delta)$ is constant and is equal to the average thickness value along the length of condenser pipe. The average value $\delta$ was calculated on the base of typical experimental data about the quantity of incoming dichlorobenzene into the condenser pipe per unit time.
(6) Convection from condensate film to internal pipe surface was not taken into account. The fraction of convective heat transfer through a layer of condensed liquid is comparatively small under concerned conditions of heat and mass transfer process. For example, laminar flow occurs at velocity $U_{0}=0.1 \mathrm{~m} / \mathrm{s}$ of a working substance at pipe axis and at viscosity $v_{2} \approx 150 \cdot 10^{-6} \mathrm{~m}^{2} / \mathrm{s}$ of condensate. The heat transfer process in the condensate film is characterized by the conduction (correlation of convection and conduction heat flux is about $3: 100$ ).

\section{Mathematical Model and Solution Method}

Heat and mass transfer processes with a phase transition in the pipes of the condenser setup (Figure 2) were described by the system of nonstationary differential equations in the Cartesian coordinates.

Heat-balance equation for the working substance in the condensation area $\left(T_{1}=T_{s}, 0<x<x_{1}, 0<y<y_{1}\right)$ :

$$
\frac{\partial T_{1}}{\partial t}+U_{1} \frac{\partial T_{1}}{\partial x}+V_{1} \frac{\partial T_{1}}{\partial y}=a_{1}\left(\frac{\partial^{2} T_{1}}{\partial x^{2}}+\frac{\partial^{2} T_{1}}{\partial y^{2}}\right) .
$$

Thermal conduction equation for the working substance out of the condensation area $\left(T_{1}<T_{s}, 0<x<x_{1}, y_{1}<y<y_{2}\right)$ :

$$
\frac{\partial T_{2}}{\partial t}=a_{2}\left(\frac{\partial^{2} T_{2}}{\partial x^{2}}+\frac{\partial^{2} T_{2}}{\partial y^{2}}\right) \text {. }
$$

Thermal conduction equation for the pipe wall $\left(0<x<x_{1}\right.$, $\left.y_{2}<y<y_{3}\right):$

$$
\frac{\partial T_{3}}{\partial t}=a_{3}\left(\frac{\partial^{2} T_{3}}{\partial x^{2}}+\frac{\partial^{2} T_{3}}{\partial y^{2}}\right)
$$


Diffusion equation for the vapors of working substance $(0<$ $\left.x<x_{1}, 0<y<y_{1}\right)$ :

$$
\frac{\partial C_{v}}{\partial t}+U_{1} \frac{\partial C_{v}}{\partial x}+V_{1} \frac{\partial C_{v}}{\partial y}=D_{1}\left(\frac{\partial^{2} C_{v}}{\partial x^{2}}+\frac{\partial^{2} C_{v}}{\partial y^{2}}\right)
$$

Motion equation for the vapors of working substance $(0<$ $\left.x<x_{1}, 0<y<y_{1}\right)$ :

$$
\rho_{1} U_{1} \frac{\partial U_{1}}{\partial x}+\rho_{1} V_{1} \frac{\partial U_{1}}{\partial y}=-\frac{\partial P_{1}}{\partial x}+\mu_{1} \frac{\partial^{2} U_{1}}{\partial y^{2}} .
$$

Continuity equation for the vapors of working substance $(0<$ $\left.x<x_{1}, 0<y<y_{1}\right)$ :

$$
\frac{\partial \rho_{1} U_{1}}{\partial x}+\frac{\partial \rho_{1} V_{1}}{\partial y}=0
$$

Equation of state for the vapors of working substance $(0<$ $\left.x<x_{1}, 0<y<y_{1}\right)$ :

$$
P_{1}(x, y)=\frac{\rho_{1}(x, y)}{M_{1}} R_{t} T_{1}(x, y) .
$$

Initial conditions $(t=0)$ :

$$
\begin{aligned}
& T_{1}=T_{0} \quad \text { at } 0<x<x_{1}, \quad 0<y<y_{3} ; \\
& C_{v}=0 \text { at } 0<x<x_{1}, 0<y<y_{1} .
\end{aligned}
$$

Boundary conditions:

$$
\begin{gathered}
y=0,0<x<x_{1}: \frac{\partial T_{1}}{\partial y}=0, \quad \frac{\partial C_{v}}{\partial y}=0, \quad \frac{\partial U_{1}}{\partial y}=0 ; \\
y=y_{1}, \quad 0<x<x_{1}: \\
\lambda_{1} \frac{\partial T_{1}}{\partial y}+Q_{c} W_{c}=\lambda_{2} \frac{\partial T_{2}}{\partial y}, \quad T_{1}=T_{2}, \\
-\rho_{1} D_{1} \frac{\partial C_{v}}{\partial y}=W_{c}, \quad U_{1}=0, \quad V_{1}=0 ; \\
y=y_{2}, 0<x<x_{1}: \lambda_{2} \frac{\partial T_{2}}{\partial y}=\lambda_{3} \frac{\partial T_{3}}{\partial y}, \quad T_{2}=T_{3} ; \\
y=y_{3}, 0<x<x_{1}: \alpha\left(T_{3}-T_{o}\right)=\lambda_{3}\left(\frac{\partial T_{3}}{\partial y}\right) ; \\
x=0,0<y<y_{1}: T_{1}=T_{i}, \quad U_{1}=U_{0} ; \\
V_{1}=V_{0}, \quad C_{v}=C_{0} ; \\
x=0, x=x_{1}, \quad y_{2}<y<y_{3}: \frac{\partial T_{3}}{\partial x}=0 . \\
x=x_{1}, 0<y<y_{1}: \frac{\partial^{2} T_{1}}{\partial x^{2}}=0, \quad \frac{\partial^{2} C_{v}}{\partial x^{2}}=0 ; \\
x=x_{1}<y<y_{2}: \frac{\partial T_{2}}{\partial x}=0 ;
\end{gathered}
$$

The density of vapors in the condenser pipe was calculated by a formula:

$$
\rho_{1}=M_{1} C_{v}
$$

The velocity of vapor condensation was defined by a formula:

$$
W_{c}=\frac{\beta}{1-k_{\beta} \beta} \frac{\rho_{1}}{\rho_{1 i}} \frac{\left(P_{1}^{n}-P_{1}\right)}{\sqrt{2 \pi R_{t} T_{1} / M_{1}}} .
$$

The following designations were accepted in (1)-(18): $T$ : temperature, $\mathrm{K}$; $t$ : time, $\mathrm{s} ; x$, $y$ : coordinate axes of the Cartesian system, $\mathrm{m} ; U, V$ : velocity components in the projections on $x$-and $y$-axis, $\mathrm{m} / \mathrm{s} ; a$ : temperature conductivity coefficient, $\mathrm{m}^{2} / \mathrm{s} ; C_{v}:$ molar concentration, $\mathrm{mol} / \mathrm{m}^{3} ; D$ : diffusion coefficient, $\mathrm{m}^{2} / \mathrm{s} ; \rho$ : density, $\mathrm{kg} / \mathrm{m}^{3} ; P$ : pressure, $\mathrm{N} / \mathrm{m}^{2} ; \mu$ : coefficient of dynamic viscosity, $\mathrm{kg} /(\mathrm{m} \cdot \mathrm{s}) ; M$ : molal mass, $\mathrm{kg} / \mathrm{mol} ; R_{t}$ : absolute gas constant, $\mathrm{J} /(\mathrm{mol} \cdot \mathrm{K}) ; T_{0}$ : initial temperature, $\mathrm{K} ; \lambda$ : heat conduction coefficient, $\mathrm{W} /(\mathrm{m} \cdot \mathrm{K}) ; \mathrm{Q}_{c}$ : energy of phase transition, $\mathrm{J} / \mathrm{kg} ; W_{c}$ : condensation velocity, $\mathrm{kg} /\left(\mathrm{m}^{2} \cdot \mathrm{s}\right)$; $\alpha$ : heat-exchange coefficient, $\mathrm{W} /\left(\mathrm{m}^{2} \cdot \mathrm{K}\right) ; T_{o}$ : surrounding temperature, $\mathrm{K} ; T_{i}$ : vapor temperature at the channel inlet, $\mathrm{K} ; U_{0}, V_{0}$ : initial velocity, $\mathrm{m} / \mathrm{s} ; C_{0}$ : vapor concentration at the channel inlet $\left(C_{0}=\rho_{1 i} / M_{1}\right), \mathrm{mol} / \mathrm{m}^{3} ; \rho_{1 i}$ : vapor density at the channel inlet, $\mathrm{kg} / \mathrm{m}^{3} ; \beta$ : condensing coefficient $(\beta=0.1[9])$; $k_{\beta}$ : extra factor equal to 0.4 [9]; $P^{n}$ : saturated vapor pressure, $\mathrm{N} / \mathrm{m}^{2}$; indexes " 1 ," " 2 ," and " 3 " correspond to dichlorobenzene vapors, dichlorobenzene liquid, and material of condenser pipes.

The system of nonstationary differential equations (1)(7) with the corresponding initial (9) and boundary (9)-(16) conditions was solved by the finite difference method [10]. The difference analogs of differential equations were solved by the locally one-dimensional method. The sweep method using the implicit four-point scheme was applied to solve the one-dimensional difference equations. The method of simple iterations was applied to solve the nonlinear equations. Verification of the obtained numerical research results was based on the conservatism of the applied difference scheme [11-15].

\section{Results and Discussion}

The numerical investigations were carried out for the typical values of condenser parameters (Figure 2). The initial temperature (corresponding saturated state) of a working substance at the condenser inlet for dichlorobenzene $T_{1 d}=$ $426 \mathrm{~K}$ and for PES-5 $T_{1 p}=530 \mathrm{~K}$. The phase transfer heat effect for dichlorobenzene $Q_{c 1}=311.7 \cdot 10^{3} \mathrm{~J} / \mathrm{kg}$ and for PES-5 $Q_{c 2}=200 \cdot 10^{3} \mathrm{~J} / \mathrm{kg}$. The molecular mass for dichlorobenzene $M_{1}=147 \mathrm{~kg} / \mathrm{kmol}$ and for PES-5 $M_{2}=1617 \mathrm{~kg} / \mathrm{kmol}$. Rates of solution area $H_{x}=50 \cdot 10^{-3} \mathrm{~m}, H_{y}=1500 \cdot 10^{-3} \mathrm{~m}$. The dimensionless evaporation coefficient $\beta=0.1$. The motion velocity of working substance in the condenser $V_{1}=0.01 \mathrm{~m} / \mathrm{s}$. The heat transfer coefficient $\alpha_{1-2}=650 \mathrm{~W} /\left(\mathrm{m}^{2} \cdot \mathrm{K}\right)$. The thermophysical properties of dichlorobenzene, PES-5, steel, and air are listed in $[7,16,17]$. 


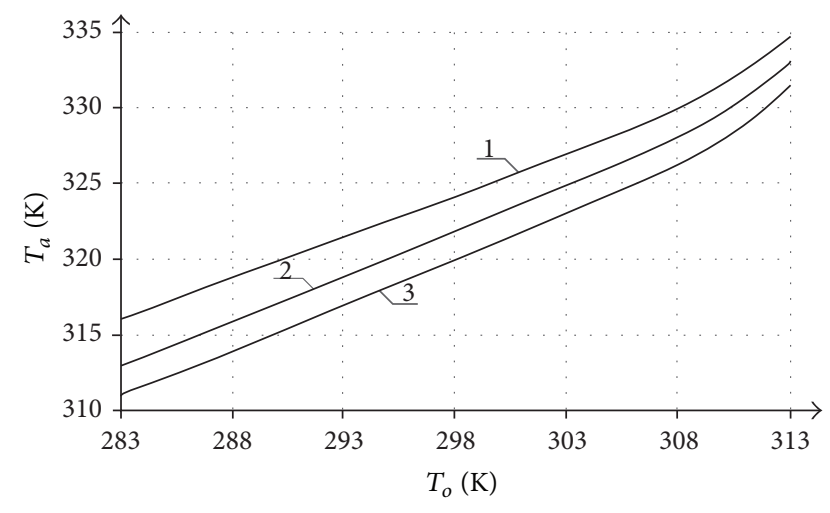

FIGURE 4: The dependences of the outlet working liquid temperature $T_{a}$ on the outside cooling air temperature $T_{o}$ under the conditions: 1: $\alpha_{a}=10 \mathrm{~W} /\left(\mathrm{m}^{2} \cdot \mathrm{K}\right) ; 2: \alpha_{a}=20 \mathrm{~W} /\left(\mathrm{m}^{2} \cdot \mathrm{K}\right) ; 3: \alpha_{a}=30 \mathrm{~W} /\left(\mathrm{m}^{2} \cdot \mathrm{K}\right)$.

Figure 4 shows the dependences of working flow outlet temperature on the outside cooling air temperature at the different values of heat transfer coefficient $\left(\alpha_{a}\right)$ between the outer surface of condenser pipe and surrounding air. The heat transfer coefficient values correspond to the range from the natural convection to the turbulent on condition that the fan blower of additional refrigeration system of the condenser operates.

It was shown that the vapor temperature at the outlet of the condenser setup pipe is decreased sufficiently moderately when increasing the heat transfer coefficient $\left(\alpha_{a}\right)$ under the condition of constant outside air temperature. It means relatively low efficiency of additional air cooling (by air fan) for condenser pipes. Such method of cooling is widely used on the mini thermal power plants [6] being operated on the objects of the Far East gas pipeline system. The obtained result allows making a supposition concerning the great importance of temperature gradient on the "pipe wall, outside air" border for the considered heat and mass transfer processes.

There are several methods of the heat transfer enhancement for the condenser. The first one is finned tubes [8] using for modification of setup construction. The second one is creation of turbulent conditions inside the pipes of condenser setup by the building-up of undulating surface or dovetails [8]. The last method allows significantly increasing the heat transfer coefficient. However, the flow friction will increase inside the pipes and it is highly undesirable under the conditions of working fluid moving internally cooling tubes (especially, for the organic coolants). The third method is the application of water flow for heat transfer surface cooling [8]. As a rule, the heat transfer coefficient values between the outer surface of the channel and water flow are about the several hundreds of $\mathrm{W} /\left(\mathrm{m}^{2} \cdot \mathrm{K}\right)$. Therefore, it is very interesting to analysis of possible operation modes of the mini thermal power plant condenser in case of construction modification and application of the water cooling instead of the air cooling.

The dependences of the outlet working liquid temperature on the outside cooling water temperature at the different values of $\alpha_{w}$ are illustrated in Figure 5.

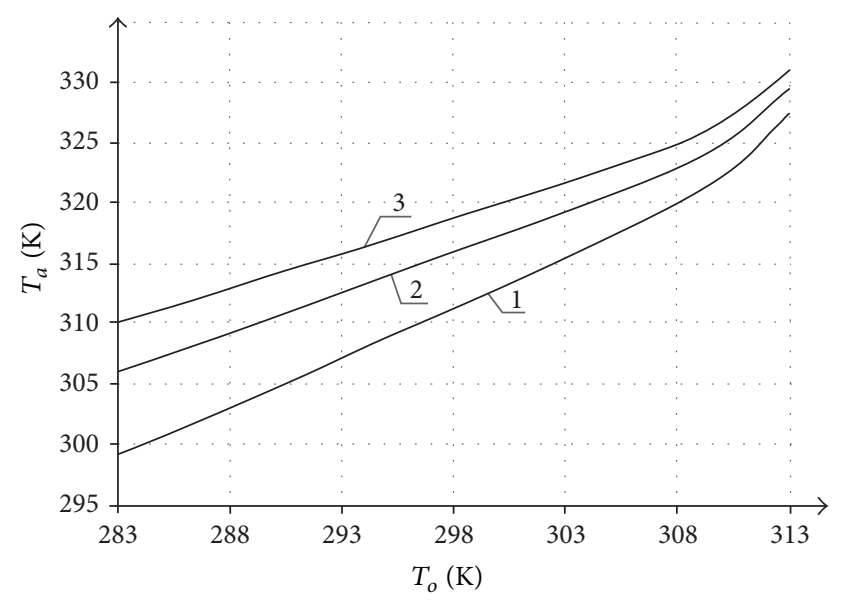

FIgURE 5: The dependences of the outlet working liquid temperature $T_{a}$ on the outside cooling water temperature $T_{o}$ under the conditions: $1: \alpha_{w}=300 \mathrm{~W} /\left(\mathrm{m}^{2} \cdot \mathrm{K}\right) ; 2: \alpha_{w}=200 \mathrm{~W} /\left(\mathrm{m}^{2} \cdot \mathrm{K}\right) ; 3: \alpha_{w}=$ $100 \mathrm{~W} /\left(\mathrm{m}^{2} \cdot \mathrm{K}\right)$.

The numerical research results listed in Figure 5 testify to the necessity to provide more efficient condensing and cooling conditions for the working flow in comparison with the air cooling system. Outlet temperature values are differently no less than $5 \mathrm{~K}$ at the similar values of cooling water temperature for corresponding system.

However, it should be considered that the significant modification of condenser design is required to provide the water cooling of condenser pipes on the independent powersupply plant (Figure 2). Furthermore, the use of water cooling system is characterized by the additional energy expenditure for pumping of working liquid. This weakness can be the very important argument for avoiding the use of such system for independent power-supply plant given the shortage of centralized power supply.

The comparative analysis of the dependences of the two phase working flow temperature at the condenser outlet on outside cooling air temperature was carried out for different organic coolants with lubricating properties (dichlorobenzene and polyethylsiloxane PES-5). The purpose of this investigation is to assess the feasibility of a typical working substance changing to another organic coolants with lubricating properties for improving the efficiency of the process.

The dependences shown in Figure 6 allow giving findings that dichlorobenzene (curve number 2) has a more scale impact than PES-5 on the heat and mass transfer processes taking place in the condenser pipe of independent powersupply plant. The outlet dichlorobenzene temperature is changed no less than $30 \mathrm{~K}$ under the condition of outside air temperature variation in a range of $T_{o}=253-313 \mathrm{~K}$.

The outside air temperature impact on the condensing process is less (curve number 1) in case of using polyethylsiloxane PES-5 as organic working substance in the closedlooped thermodynamic cycle of power-supply plant. The outlet PES- 5 temperature is changed less than $20 \mathrm{~K}$ under the condition of outside air temperature variation in a range of $T_{o}=253-313 \mathrm{~K}$. However, more favorable conditions for 


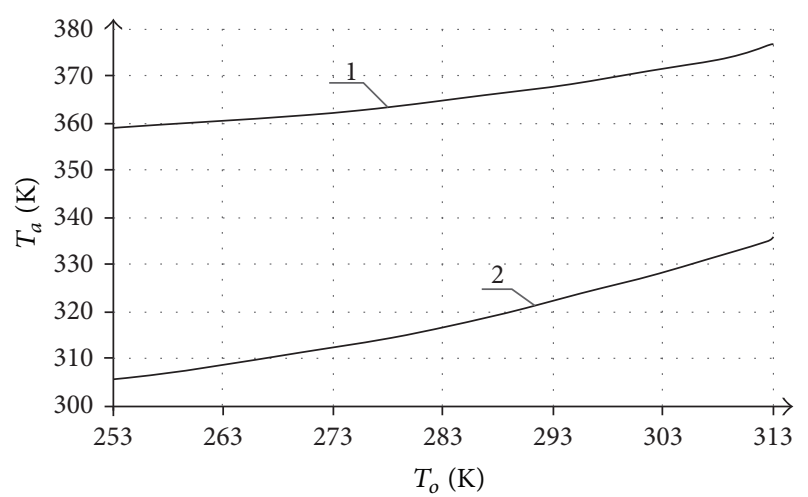

Figure 6: The dependences of the two phase working flow temperature at the condenser outlet $T_{a}$ on the outside cooling air temperature $T_{o}: 1$ : PES-5; 2: dichlorobenzene.

vapor condensing of organic working substance are realized for polyethylsiloxane. It can be explained by the more higher difference between the values of boiling temperature and outlet temperature for PES-5 (about $145 \mathrm{~K}$ ) than analog parameter for dichlorobenzene (about $140 \mathrm{~K}$ ).

The condensing process under the conditions of low cooling air temperature $\left(T_{o}=253 \mathrm{~K}\right)$ is more intensive in the case of PES-5 usage as a working substance. The difference between the values of saturation temperature and outlet temperature for PES-5 is about $160 \mathrm{~K}$. Analog parameter for dichlorobenzene is about $120 \mathrm{~K}$.

The obtained numerical research results can be explained by the fact that organosilicone working substance PES-5 has significantly higher (in comparison with dichlorobenzene) condensation temperature $\left(T_{s} \approx 520 \mathrm{~K}\right)$. The sufficiently large temperature gradient between the wall of condenser pipe and the cooling air occurs even under the conditions of high temperature value for last one.

However, it should be noted that the application of polyethylsiloxane PES-5 as a working substance in the closedlooped thermodynamic cycle of independent power-supply plant would require the implementation of all technological operations under the condition of a significantly higher temperature. This may lead to reliability degradation of individual components, and power-supply plant as a whole. However, the application of alternative organic substance in the thermodynamic cycle is possible after modernization and testing of different components.

\section{Conclusions}

According to conducted numerical investigations, it was established that the water cooling of heat transfer tubes in the condenser of independent power-supply plant is more effective in comparison with the air cooling system. However, the application of water cooling system is possible after the condenser modernization.

The numerical analysis of integral characteristics for the condensing process of two organic working substances allowed us to formulate the conclusion about the practical application of a working substance with higher condensation temperature under the considered operation conditions. However, the additional detailed investigation of thermodynamic cycle high temperature influence on the components of electric power plant is necessary. Also alternative organic substance should be tested for use as friction bearing lubrication of turbogenerator rotor.

\section{Conflict of Interests}

The authors declare that there is no conflict of interests regarding the publication of this paper.

\section{Acknowledgment}

This work was supported by The Global Energy Non-Profit Partnership (code of project MG-2014/04/3).

\section{References}

[1] C. Dickey, "The next new oil is a gas," Newsweek, vol. 144, no. 12, p. 28, 2004.

[2] A. Kontorovich, A. Korzhubaev, and L. Eder, "Prospects for Russian natural gas exports to APR countries: resources, technologies, and geopolitics," Far Eastern Affairs, vol. 36, no. 3, pp. 57-73, 2008.

[3] E. Pronin, R. Samsonov, and I. Malenkina, "Prospects for expansion of international transport corridors Russia-Europe with the use of natural gas as motor fuel," in Proceedings of the 24th International Gas Union World Gas Conference (WGC '09), Buenos Aires, Argentina, 2009.

[4] Quarterly Report on European Electricity Markets, Market Observatory for Energy, vol. 6, no. 2, 2013.

[5] O. V. Vysokomornaya, V. S. Vysokomorny, and P. A. Strizhak, "Analysis of the reasons technical incidents to independent sources of electricity the unified gas supply system of Russia," Power Engineer, vol. 8, pp. 31-36, 2013 (Russian).

[6] Ormat Systems Ltd, EPS Operation and Maintenance Manual (powered by CCVT), Part 2, Ormat Systems Ltd, 2006.

[7] Y. M. Babikov, Organic and Organosilicone Heat Conductors, Energia, Moscow, Russia, 1975, (Russian).

[8] H. Y. Wong, Handbook of Essential Formulae and Data on Heat Transfer for Engineers, Longman Group, London, UK, 1977.

[9] C. Kothandaraman and S. Subramanyan, Heat and Mass Transfer Data Book, Halsted Press/Wiley, Hoboken, NJ, USA, 1975.

[10] A. A. Samarskii, The Theory of Difference Schemes, Marcel Dekker, 2001.

[11] G. V. Kuznetsov and P. A. Strizhak, "Gas-phase ignition of a film of liquid condensed substance by a metal particle heated to high temperatures under mixed-convection conditions," Journal of Engineering Physics and Thermophysics, vol. 82, no. 6, pp. 10661072, 2009.

[12] O. V. Vysokomornaya, G. V. Kuznetsov, and P. A. Strizhak, "Numerical analysis of heat-mass transfer mechanisms in gasphase ignition of films of liquid condensed substances by a laser beam," Journal of Engineering Thermophysics, vol. 19, no. 2, pp. 85-93, 2010.

[13] G. V. Kuznetsov and P. A. Strizhak, "Transient heat and mass transfer at the ignition of vapor and gas mixture by a moving 
hot particle," International Journal of Heat and Mass Transfer, vol. 53, no. 5-6, pp. 923-930, 2010.

[14] D. O. Glushkov and P. A. Strizhak, "Transient heat and mass transfer of liquid droplet ignition at the spreading over the heated substrate," Advances in Mechanical Engineering, vol. 2014, Article ID 269321, 9 pages, 2014.

[15] D. O. Glushkov, G. V. Kuznetsov, and P. A. Strizhak, "Numerical investigation of water droplets shape influence on mathematical modeling results of its evaporation in motion through a hightemperature gas," Mathematical Problems in Engineering, vol. 2014, Article ID 920480, 8 pages, 2014.

[16] N. B. Vargaftik, Tables of Thermophysical Properties of Liquids and Gases, Hemisphere Publishing, New York, NY, USA, 1975.

[17] Liquid Materials Handbook, The Atomic Energy Commission, Department of the Navy, Washington, DC, USA, 1952. 


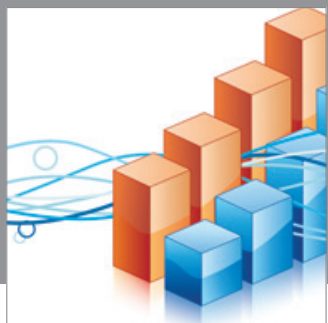

Advances in

Operations Research

mansans

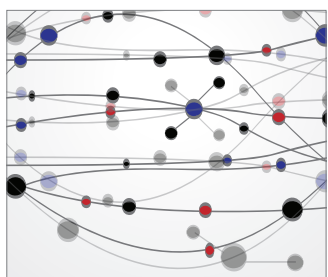

The Scientific World Journal
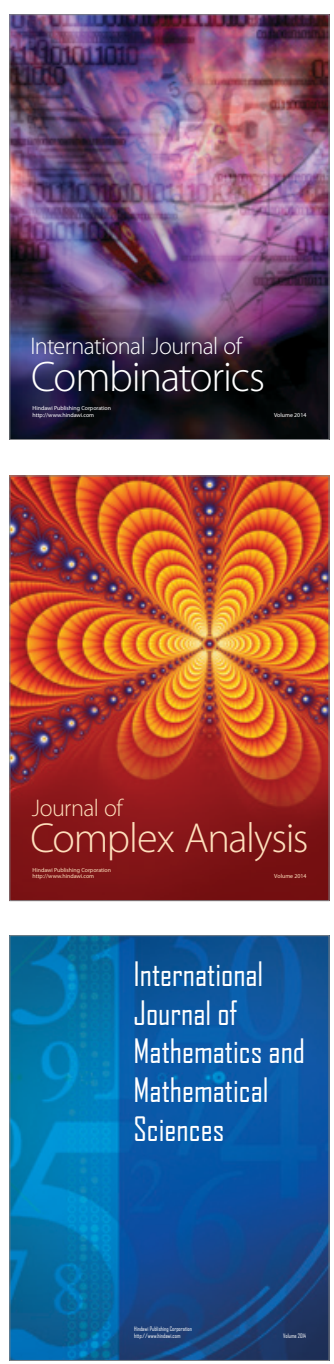
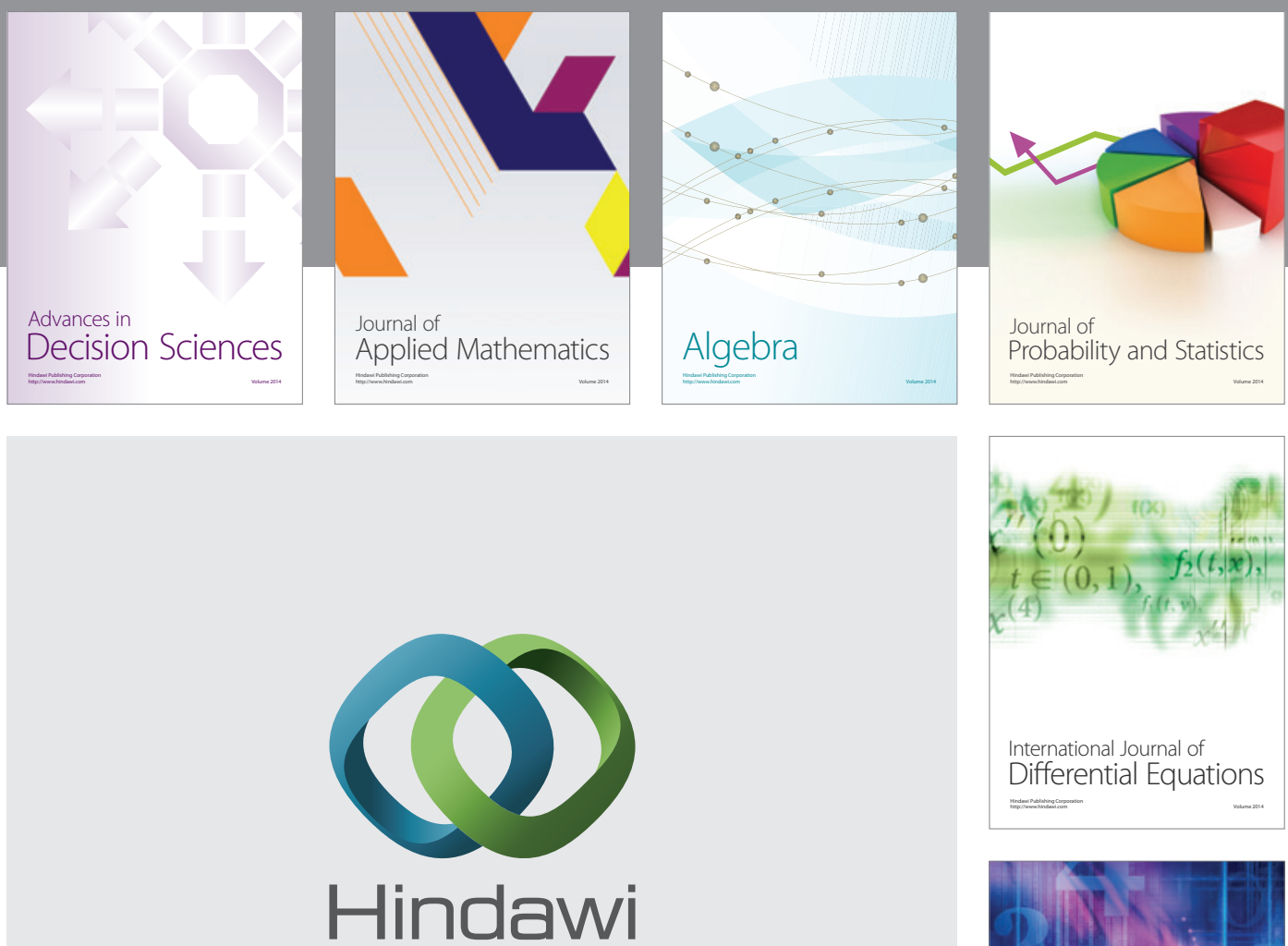

Submit your manuscripts at http://www.hindawi.com
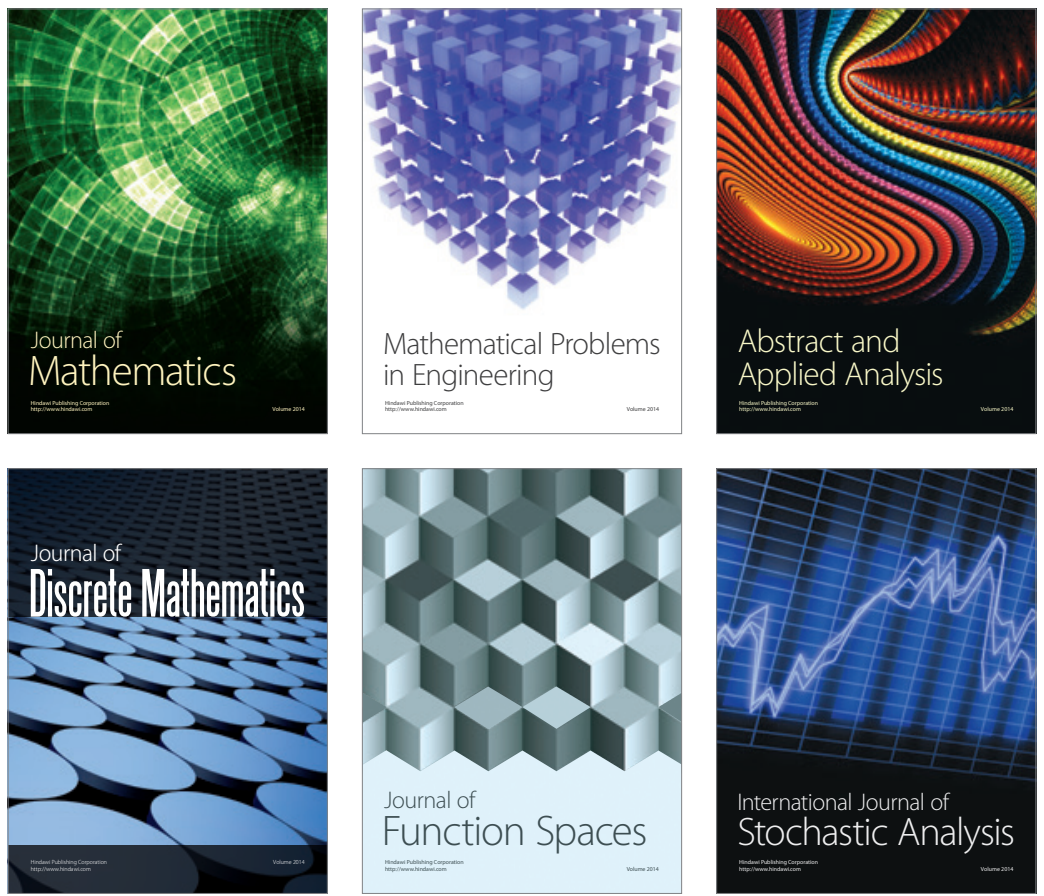

Journal of

Function Spaces

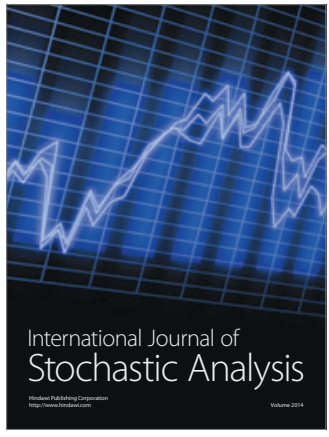

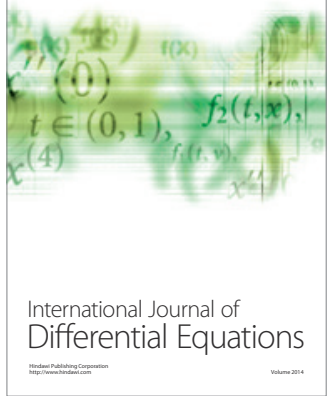
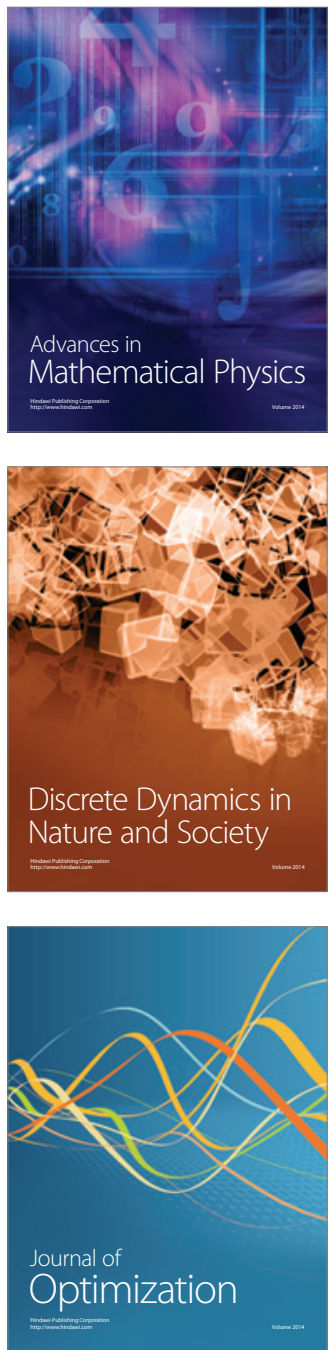